\title{
Editorial
}

\section{Mais atenção na Atenção Básica}

Silvio Gomes Monteiro

Conforme a Constituição Federal de 1988, a "Saúde é direito de todos e dever do Estado". Visando atingir esse ideal foi publicada no Diário Oficial da União $n^{\circ} 148$, de 4 de agosto de 2008, a Portaria GM n. 1559, de $1^{\circ}$ de agosto de 2008, que instituiu a Política Nacional de Regulação do Sistema Único de Saúde (SUS), a ser implantada em todas as unidades da Federação. Com isso se estabeleceu como a "porta de entrada" dos usuários nos sistemas de saúde a atenção básica ou atenção primária em saúde. Assim a Atenção Básica é o atendimento inicial. Seu objetivo é orientar sobre a prevenção de doenças, solucionar os possíveis casos de agravos e direcionar os mais graves para níveis de atendimento superiores em complexidade. A atenção básica funciona, portanto, como um filtro capaz de organizar o fluxo dos serviços nas redes de saúde, dos mais simples aos mais complexos. E para a realização dessa meta várias são as frentes de trabalho da atenção básica, algumas relacionadas com a saúde da criança, saúde da mulher, saúde do idoso e o acompanhamento de diversas doenças crônicas, tais como, hipertensão arterial, diabetes, hanseníase, câncer de colo e de mama, câncer de próstata. Assim com uma boa cobertura da atenção primária, cerca de $85 \%$ dos problemas de saúde terão $95 \%$ de resolução. Isso para os governos, municipal, estadual e federal, representa uma enorme redução de custos.

Por isso que dos 12 artigos do segundo fascículo do volume 10 da $\underline{\text { Revista }}$ de Investigação Biomédica $(R I B)$, contém quatro artigos que estão relacionados com a saúde da mulher, um sobre autocuidado de pacientes com diabetes, um artigo sobre pacientes com insuficiência cardíaca e outro sobre insuficiência renal. No atual fascículo de 2018 terá os seguintes temas:

- Análise da atividade antimicrobriana do extrato hidroalcoólico das folhas de Terminalia catappa contra Staphyloccocus aureus e Staphylococcus aureus resistente a meticilina - MRSA

- Comparação do perfil de sensibilidade antifúngica de isolados de criptocócos de lesões cutâneas de pacientes diagnósticos de HIV / AIDS em um hospital público em São Luís - MA

- Fatores predisponentes na prevalência da candidíase vulvovaginal

- Atividade antifúngica de extratos hidroalcoólicos em isolados de Candida obtidos de secreção vaginal.

- Adesão dos pacientes de diabetes mellitus às atividades de autocuidado

- Prevalência de automedicação em profissionais de saúde de um hospital privado de São Luís - MA

- Perfil clinico-epidemiológico de pacientes com insuficiência cardíaca internados em hospital público de São Luís - MA 
- Exposição a mídia e hábitos alimentares de adolescentes em uma escola privada de São Luís - MA

- Identificação de bactérias presentes em biofilmes de superfícies metálicas

- Modelo alternativo de tratamento de vulvovaginite causada por Candida glabrata com uma fração de N-butanol das folhas de Terminalia catappa

E há também dois artigos de revisão, cujos temas abordados são:

- Efetividade da adesão de sistemas adesivos universais que contém silano em dissilicato de lítio

- Pacientes com insuficiência renal crônica em hemodiálise: tratamento e diagnóstico

Que essas novas pesquisas ajudem a ampliar o horizonte dos vossos conhecimentos sobre a realidade dos problemas de saúde da população brasileira e que assim contribuam para melhorar a qualidade da Atenção Básica que é oferecida à nossa população.

Prof. Silvio Gomes Monteiro

Editor-Chefe 